\title{
OS MORTOS NO LIMIAR E NO ALÉM-TÚMULO EM VASOS FIGURADOS ETRUSCOS (SECULOS IV E III a.C.)
}

\author{
Roseli Fellone \\ Universidade de São Paulo
}

Resumo: A concepção etrusca acerca da vida após a morte é expressa também nos vasos figurados com cenas funerárias. Dentre esses vasos selecionamos cinco que apresentam o morto em dois momentos distintos: no momento em que ele/a se dirige para o Inferno, o limiar entre o mundo dos vivos e dos mortos, tratado nos três primeiros vasos, e, por fim, no momento em que o morto/a já se encontra no Inferno. Estes dois eixos de representação apontam não só para a discussảo dos referenciais temático e ideográfico delineadores de suas concep̧̧̃es como, ainda, permitem de imediato visualizar a diferença no instante da passagem para determinados mortos tal qual o destino que os aguarda. Uma afirmação mais conclusiva diz respeito à importáncia do referencial iconográfico grego na concretização das concepções etruscas relativas à morte $\theta$, como contraponto, à particularidade dessas representaçōes iconográficas etruscas.

Palavans-Chave: Além-Túmulo, Limiar, Inferno, Iconografia, Imagística, Eixos, Repertório, Ritos Funerários, Crenças.

Na Etrúria, a partir do século IV a.C. há uma significativa produção de vasos figurados com cenas funerárias e infernais. Esta temática funerária e infernal não é um acontecimento que se encontra isolado na produção cerâmica, pois em outros materiais, como urnas, sarcofagos, pinturas murais e espelhos, 0 mesmo tema é recorrente. Durante o período compreendido entre os séculos IV e II a.C., vemos esta produção iconográfica especifica ligada às concepçōes etruscas acerca da morte e do Inferno que evidencia a preocupação de uma elite, para quem são produzidos estes objetos, com sua situação religiosa.

Apesar da particularidade dessas representaçōes, dada por sua natureza (a morte tida como inevitável e até brutal) e da presença de personagens tipicamente etruscos (os demônios Charun, Tuchulcha e Vanth), a formação do repertório iconográfico etrusco fez-se através do repertório iconográfico grego: seja pela apropriação da imagem de certas divindades como Hades, Perséfone, Hermes e de seus devidos atributos; seja pelo emprego de certos temas como 0 dos supliciados no Inferno ou, ainda, pelo tratamento temático, como veremos mais adiante.

Selecionamos duas temáticas bastante proximas, relativas ao mundo infernal e funerário, mas diferenciadas por sua localização: as representaçōes dadas no próprio Inferno, no além-túmulo, e as representaçōes do seu espaço mais próximo, do seu limiar. Com esta seleção, tencionamos realizar inferências pontuais e apontar a origem, as correlaçōes e as mudanças desse repertório iconográfico etrusco. 
Discutiremos uma série de cinco vasos onde o morto apresenta-se em dois momentos distintos: no momento em que ele se dirige para o Inferno, o limiar entre o mundo dos vivos e dos mortos, e no momento em que ele já se encontra no mundo dos mortos.

Para cada uma dessas duas situações, escolhemos três e dois vasos respectivamente e nos parece imprescindivel apontar na iconografia os termos que identificam um espaço tão fluente como aquele do limiar em contraposição com 0 Inferno ${ }^{1}$, "locus per si". Iconograficamente, a representação deste espaço de passagem é dada pela ausência de elementos ou personagens infernais, como Cérbero, Hades e Perséfone, e pela não especificação espacial. Por outro lado, sua construção requer, na maioria das vezes, a presença de demônios infernais, Charun ou Vanth, e mesmo de Hermes psicopompo, que acompanham o morto na sua jornada em direção ao Inferno.

No stamnos de Bomarzo (fig. 1), encontramos no verso do vaso, à esquerda, Charun segurando um martelo contra o peito. No centro, um cavalo a galope é montado por um cavaleiro, 0 morto, que soando uma trombeta volta-se para uma mulher que traz levantada na mão direita uma cista. No reverso, um homem barbado e enrolado em um manto está deitado em uma carroça puxada por mulas.

A cena do verso situa-se no limiar do Inferno e Charun conduz o cavaleiro morto. Diversas urnas etruscas de Volterra, do Museu Guarnacci (BRUNN e KÖRTE I, 1870, pr. LXIX e LXX), têm representada a viagem a cavalo do morto, seguido por um servo conforme 0 esquema: demônio, cavaleiro, servo. Tal esquema corresponde a um tema decorativo das estelas funerárias gregas: a viagem a cavalo do morto heroicizado, acompanhado de um servo ou posto diante de um altar no qual uma mulher faz a libação. Em uma urna do Museu Gregoriano (DE RUYT, 1934, p. 199), o defunto a cavalo é seguido pelo servo que carrega no ombro esquerdo um saco e na mão direita um gládio, sob as patas do cavalo está um boné frígio; à direita, uma mulher assiste a partida.

A representação desta jornada em direção ao Inferno é freqüente não só nos vasos como nas urnas. E segundo sua condição social, o morto pode ser transportado a pé, a cavalo ou em um carro'.

Porém o reverso do vaso, figurando um homem deitado em uma carroça puxada por mulas, também trata da viagem do morto para o Inferno mas não podemos situar esta cena no limiar devido à ausência de um demônio que atue como psicopompo ou de Hermes psicopompo. 0 mesmo tipo de representação do morto, um homem deitado em uma carroça e enrolado em um manto, encontra-se em um grande número de urnas, as quais figuram um cortejo fúnebre com acompanhamento dos familiares e nele o morto não aparece como um cadáver (BRUNN e KÖRTE I, 1870, pr. LXXX-I).

1. 0 termo Inferno é aqui empregado na sua acepção latina Inferos, designando o mundo inferior de acordo com a tradicional tripartiçăo do mundo.

$\mathrm{Na}$ iconografia etrusca é nítida a diferença de dois espaços bem próximos: 0 além-túmulo e o seu limiar. 0 Inferno é identificado iconograficamente pela presença de Hades-Aita e Perséfone-Phersipnai, seus senhores, ou, então, pela presença de Cérbero ou de serpentes. Logo, o Inferno existe como um local determinado, o além-túmulo, em contraposiçăo ao mundo dos vivos. Mas nada indica na iconografia que o Inferno seja o destino último dos mortos 
No outro vaso, stamnos de Villa Giulia (fig. 2), Hermes psicopompo defende a morta de uma Erínia. A morta apoia a mão direita no ombro de Hermes e segura na mão esquerda um tirso. A esquerda da Erínia, uma cornucópia (Figs. 1 e 2).

Hermes, neste vaso, além de sua função de psicopompo, condutor dos mortos, desempenha o papel de protetor da morta que é ameaçada pela Erínia. 0 tratamento desta última - alada, com vestimenta longa, feições regulares e serpentes nos cabelos e/ou mãos - insere-se em uma de suas muitas caracterizações: em certos vasos e mesmo em urnas se apresenta alada ou áptera com uma vestimenta curta, quitonisco, de botas, com faixas atravessadas no peito $\mathrm{e}$ tochas como as Erínias do sul da Itália; ou, então, adquire as feiçōes de Charun, notável pela aparência horrenda.

Portanto, hă uma variedade de tipos que partem inicialmente das imagens das Erínias gregas de feiçōes belas e regulares e que serão empregadas para "visualiser certaines entités religieuses étrusques comme Vanth e Nathum, désignées par des inscriptions dans certains documents, ce qui permet leur identification" (SARIAN, 1983, p. 34). Tal empréstimo a nivel imagístico é explicitado nas ânforas de número 19 e 21 do Museu Faina (fig. 4), nas quais uma mulher nua e alada é denominada Vanth.

Entretanto, as funções desempenhadas pelas Erínias-Vanth são praticamente as mesmas de Charun, com quem ela vem freqüentemente associada. Estas funçōes cobrem um leque enorme dentro da temática infernal, a saber:

- assistindo mortes violentas;

- presenciando 0 adeus do morto;

- conduzindo o defunto a pé ou a cavalo;

- no cortejo do carro funerário;

- no cortejo do carro de Hades;

- introduzindo o defunto no Inferno;

- defendendo a entrada do Inferno;

- executora;

- desempenhando o papel das Erínias gregas na Orestia de Esquilo, única função não atribulda a Charun dentre todas as outras citadas.

A ameaça da Erínia, neste nosso vaso, é rechaçada por Hermes psicopompo que serve de guia e protetor dà morta. A idéia de Hermes protetor dos mortos é presente também na Grécia e no sul da Itália; porém aqui a morta porta 0 tirso, característico dos seguidores de Dioniso, que the confere a posição de iniciada nos mistérios de Dioniso e, por isso, protegida das ameaças da Erínia. Um outro elemento relacionado a Dioniso é a cornucópia, símbolo da abundåncia.

A referência a elementos dionislacos no tratamento de temas funerários atesta-se, ainda, na cratera do Museu de Trieste (fig. 3) em que a morta acompanha tranqüilamente dois demônios - Charun e Tuchulcha - e entre eles há uma folha de parreira, um elemento dionisfaco. Em um sarcofago do Museu de Londres (BEAZLEY, 1947, p. 152), a morta segura o tirso em uma das mãos e na outra um cântaro, atributo de Dioniso. 
Poderlamos citar alguns vasos, bem como urnas, onde se evidencia a situação religiosa do morto iniciado no dionisismo, como por exemplo a cratera do Museu de Berlim (DE RUYT, 1934, fig. 19).

Assim sendo, através destes vasos apresentados, nota-se durante 0 momento da passagem, quando o morto localiza-se no limiar do mundo dos mortos, que nem todos os mortos participam da mesma condição, sendo ela definida anteriormente pela sua situação social ou religiosa. A situação social do morto não determina seu destino no além-túmulo mas estabelece a grandeza ou não do cortejo fúnebre, como na ekphora dos magistrados, e estabelece se a jornada do morto será feita a cavalo, a pé ou em um carro. Em contrapartida, a situação religiosa determina 0 destino do morto e sua tranqüilidade e proteção durante a jornada para 0 além.

Nas duas ânforas do Museu Faina (fig. 4) com representações figuradas quase idênticas, contemplamos o morto no término de sua jornada, no além-túmulo. 0 morto é guiado por Charun até Perséfone e Hades. Hades caminha atrás de Perséfone que dirige um carro puxado por monstros semelhantes a grifos. Seguindo Hades, uma Vanth porta um volumem desenrolado que tem a inscrição de seu nome. Cérbero tricéfalo é visto preso a uma grossa corrente.

As duas ânforas pouco nos permitem falar acerca da situação do morto, afora sua chegada em um local habitado por Hades e Perséfone enquanto senhores infernais.

0 assim chamado Inferno etrusco caracteriza-se iconograficamente pelos mesmos elementos do Inferno grégo: a presença de Hades, Perséfone, Cérbero e os demônios infernais, sendo exclusivo para o Inferno etrusco os demônios Charun, Tuchulcha e Vanth. Mas se nestas ânforas pouco entrevemos sobre o destino do morto no Inferno, outros vasos etruscos tratam dos supliciados no Inferno: as Danaides na sua tarefa de encherem um vaso sem fundo em um stamnos de Florença (BEAZLEY, 1947, pr. XI) e o suplício de Piritos na cratera do Museu Carcopino (BANDINELLI e GIULIANO, 1973, p. 349, fig. 401).

Portanto, nem todos gozam da mesma sorte no além-túmulo. $E$ isto se confirma nas cenas do limiar, apesar das cenas localizadas no Inferno pouco, ou quase nada, dizerem da condição do morto.

Ao recorrermos às fontes textuais ${ }^{2}$, um dos comentários dos autores romanos sobre a religiāo etrusca, 0 de Arnóbio afirma que após a morte as almas acederiam a uma imortalidade de bem-aventuranç̧a e conheceriam uma verdadeira divinização por intermédio de um ritual: 0 oferecimento do sangue de determinados animais a certas divindades ${ }^{3}$. A indicação de Arnóbio não se acha isolada, pois Servius faz referência a uma obra de Cornelius Labeo a respeito dos dil animales 4 em que ele reafirma a utilização de ritos especificos que operariam esta transformação.

2. Para uma discussão aprofundada sobre os textos referentes à religiăo etrusca ver BRIQUEL, D. Regards sur l'au-dela. In: HINARD, F.(org.) La mort, les morts of l'au-dela dans le monde romain. Actes du Coloque a Caen 1985. 1988, p. 263-277.

3. ARNOBIO. 2, 62: "neque quod Etruria libris in Acheronticis pollicatur certorum animalium sanguine, numinibus certis dato, diuinas animas fieri et ab legibus mortalitatis educi."

4. SERVIUS, Aen. 3, 168: "sicut dicit Labeo in libris qui appellantur de dis animalibus in quibus ait esse quaedam sacra quibus animae humanae uertantur in deos qui appellantur animales, quod de animis fiant. Hi autem sunt dii Penates e Viales. 
Dois outros documentos materiais colaborariam na discussão desta possivel particularidade da doutrina etrusca acerca do destino dos mortos, ambos datados do século V a.C.: um cipo de Marzabotto que representa um defunto sobre um altar, interpretado por Massa-Pairault como o morto heroicizado ou divinizado (MASSA-PAIRAULT, 1981, p. 135-154); e uma telha de Capua, proveniente de uma necrópole, que comporta uma lista de sacrificios feitos às divindades infernais por uma familia (PALLOTTINO, 1948-49, p. 159-196).

Contudo, os cinco vasos apresentados, datados do século IV a.C., permitem algumas afirmaçōes ora generalizantes, ora mais específicas e promissoras. As generalizaçōes provêem da observação direta das imagens veiculadas nestes vasos e dizem respeito à crença em uma vida após a morte, à sobrevivência de uma alma pessoal do morto que guarda 0 aspecto físico de quando vivo, e à existência de um mundo infernal. dois eixos:

A particularidade advém da natureza destas imagens que se agrupam em

- ao redor dos ritos, em relação com os costumes funerários (JANNOT, 1988, p. 279-291);

- e relativas às crenças do além-túmulo.

No primeiro grupo localizar-se-ia o reverso do stamnos de Bomarzo (fig. 1), que traz um homem barbado e deitado em uma carroça puxada por mulas. Como vimos anteriormente, tal imagem corresponde às imagens do cortejo fúnebre.

No segundo grupo estariam as imagens do limiar (verso da fig: 1, figs. 2 e 3) e do além-túmulo (fig. 4) que diretamente se referem às crenças do alémtúmulo.

Portanto, mesmo se a imagística destes vasos etruscos emprega na totalidade 0 repertório iconográfico grego na construção de alguns de seus personagens e no tratamento da temática, sua interpretação e significado são expressamente vinculados às crenças e aos ritos funerários etruscos.

REsume: La conception étrusque sur l'au-delà s'exprime aussi dans les vases figurés avec scènes funéraires. Au milieu de tout cela, nous avons separé cinq qui prèsentent le mort dans deux moments distinctifs: au moment où il/elle se rendre au Enfer, le space parmi le monde des vivants et des morts, figurée dans les trois premiers vases, et, a la fin, au moment où le mort/e dejà se trouve dans l'Enfer. Ces deux axes du représentation permettent non seulement la discussion des références thématiques et idéographiques formatrices de ses conceptions comme, encore, permettent immédiatement visualiser la différence au moment de la passage pour certains morts aussi bien que le destin qui les attend. Une affirmation plus conclusive est sur l'importance des références iconographiques grecques dans la concrétisation des conceptions étrusques sur la mort et, en opposition, la particularité de ces représentations iconographiques étrusques. 
Bibliografia

BANDinelu, R. B. e GIULIANO, A. Les étrusques et I'Italie avant Rome. Paris, Gallimard, 1973.

BEAZleY, J. D. Etruscan Vase Painting. Oxford, Clarendon Press, 1947.

BRUNN, H. e KÖRTE, G. I Rilievi delle urne etrusche I. Rome-Berlin, G. Reimer, 1870.

DE RUYT, F. Charun. Démon étrusque de la mort. Rome, Meester Wetteren, 1934.

JANNOT, J.R. Sur la représentation étrusque des morts. In: HINARD, F. (org.) La mort, les morts et l'au-delà dans le monde romain. Actes du Colloque à Caen 1985. 1988.

MASSA-PAIRAULT, F. H. Deux questions religieuses sur Marzabotto. Mélanges d'Archéologie et d'Histoire, Ecole Française de Rome. Paris, v. XCIII, p. 135154, 1981.

PALLOTINO, M. Sulla lettura e sul contenuto della grande iscrizione di Capua. Studi Etruschi; Roma, v. XX, p. 159-196, 1948-49.

SARIAN, H. Réflexions sur l'iconographie des Erynies dans le milieu grec, italiote et étrusque. Bulletin de Correspondance Héllenique. Supplément. Paris, v. XIV, p. $25-35,1983$. 

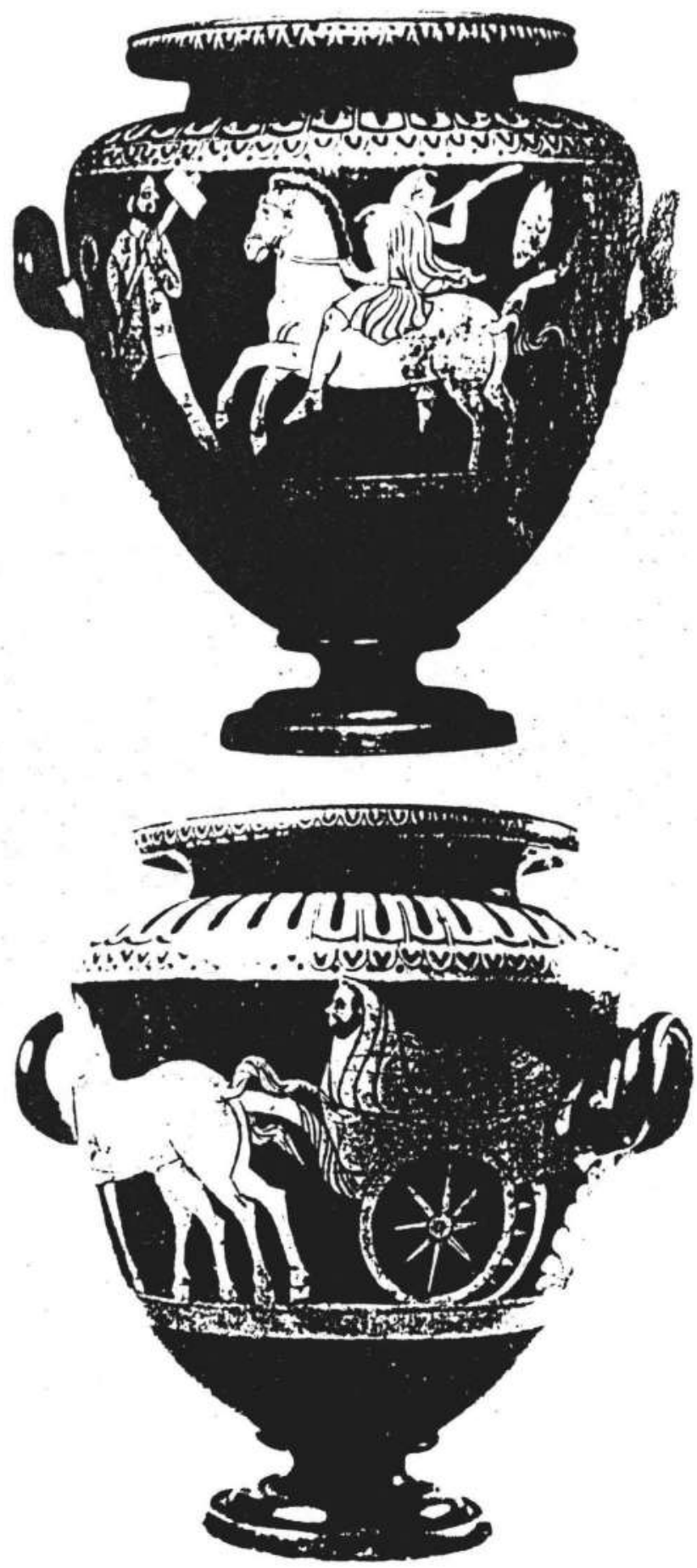

Fig. 1. Stamnos de Bomarzo. Museu de Berlim F 2954. Viagem do morto a cavalo, com Charun à esquerda; século IV a.C. (In: DE RUYT, 1934, fig. 31) Foto: Guy. 


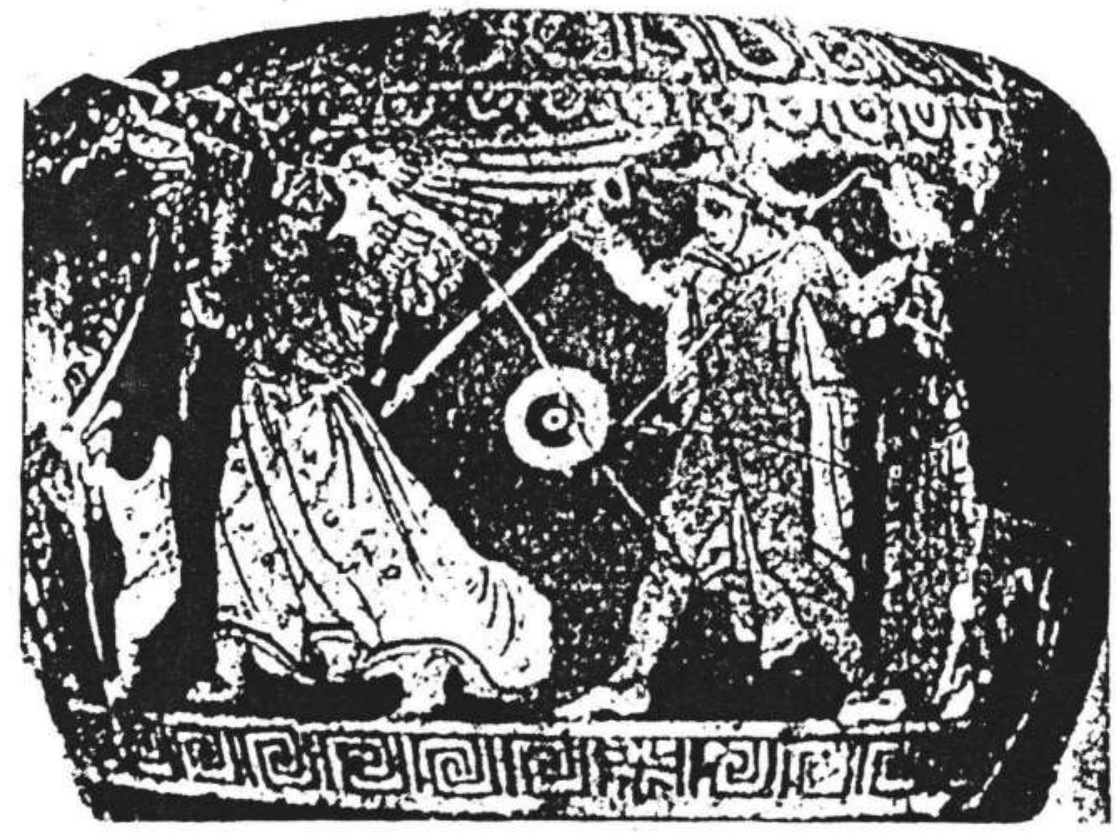

Fig. 2. Stamnos com figuras vermelhas, Museu de Villa Giulia 1660. Hermes defendendo a morta de uma Erínia; Grupo Fluído, século IV a.C. (In: BEAZLEY, 1947, pr. 35-6) 


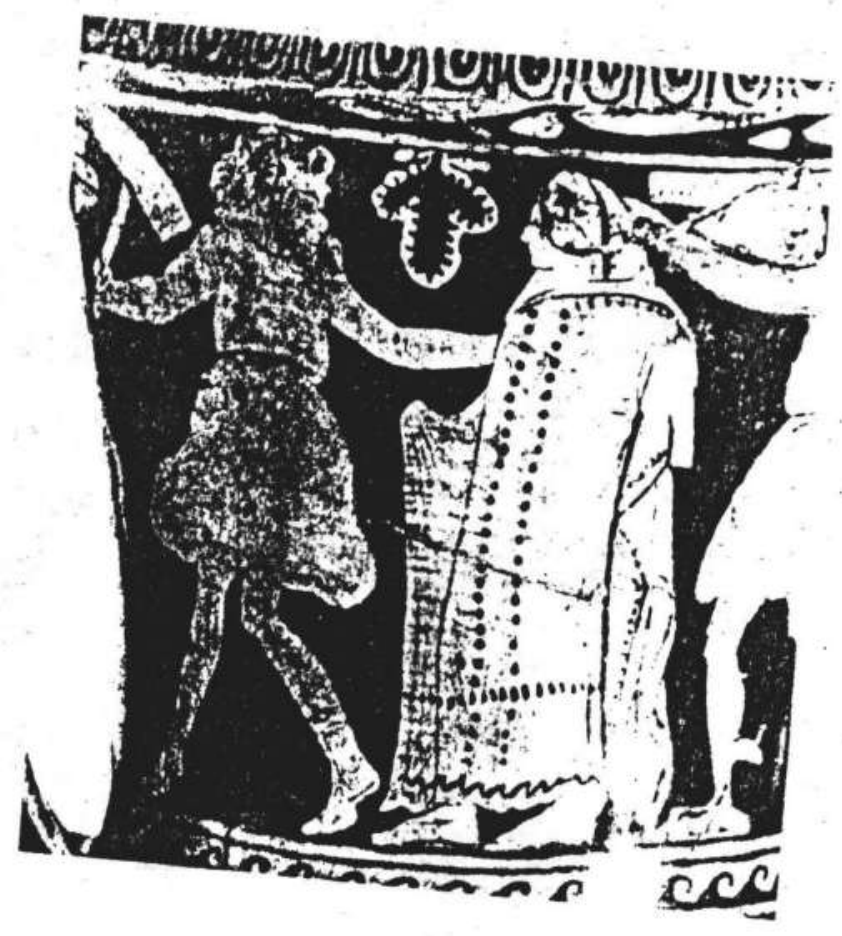

Fig. 3. Cratera em forma de cálice com figuras vermelhas, Museu Civico de Trieste 2125. A morta entre dois demônios; Grupo Alcestes, final do século IV a.C. (In: GIGLIOLI, G.Q. L'Arte Etrusca. Milão, 1935, pr. 277.1) Foto: Guy. 

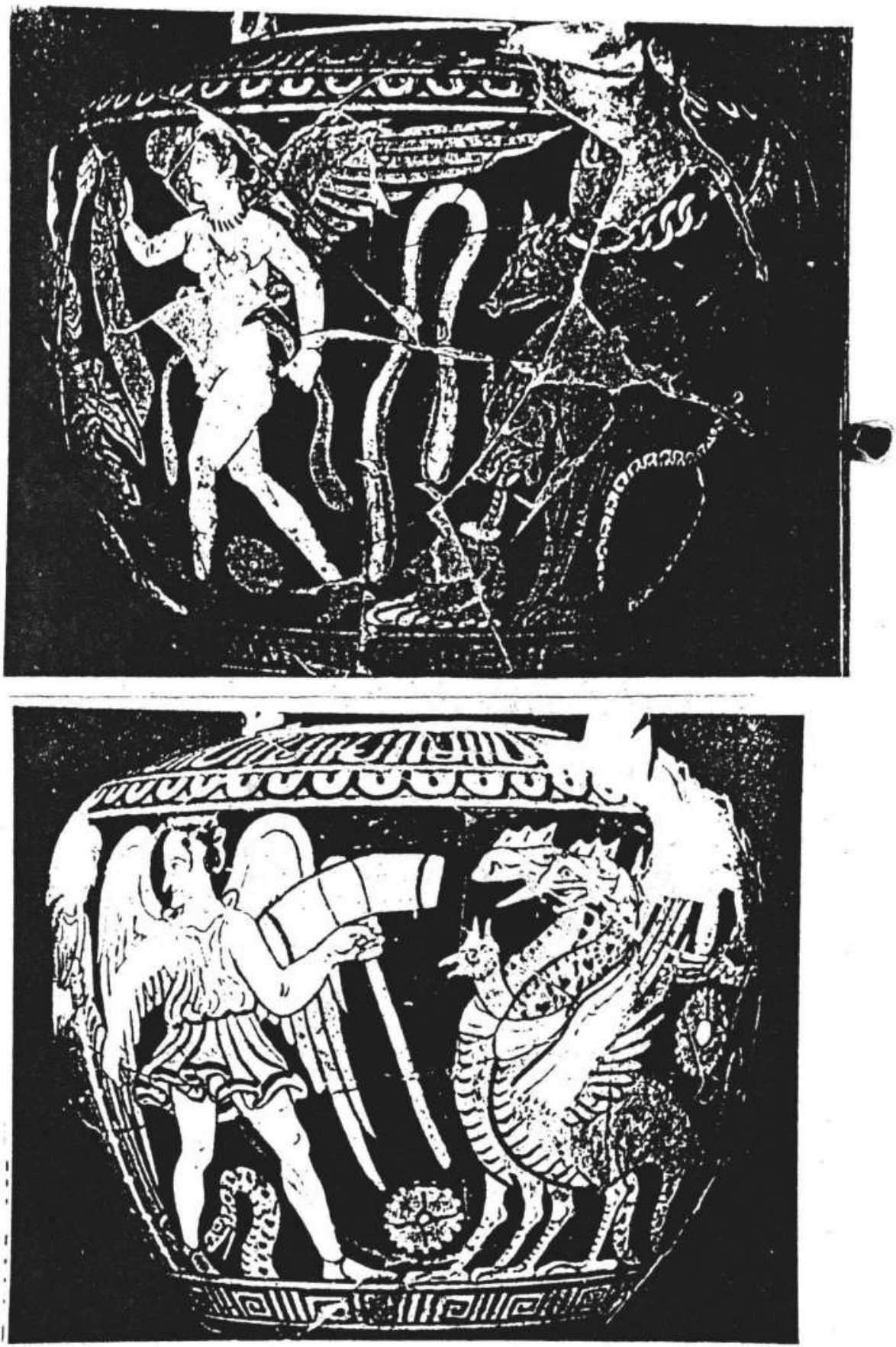

Fig. 4. Ânfora com figuras vermelhas, Museu Faina. 0 morto no Inferno, levado pela mão por Charun; Grupo Vanth, final do século IV a.C. (In:

BANDINELLI e GIULIANO, 1973, fig. 318) Foto: Guy. 